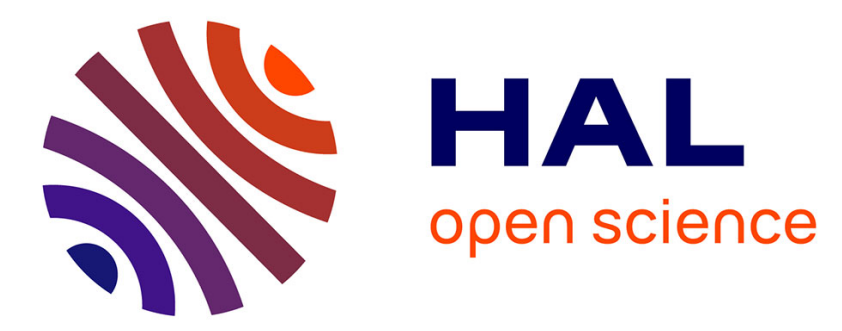

\title{
A Review on the Soil Moisture Prediction Model and Its Application in the Information System
}

Wengang Zheng, Lili Zhangzhong, Xin Zhang, Caiyuan Wang, Shirui Zhang, Shijun Sun, Hongfei Niu

\section{- To cite this version:}

Wengang Zheng, Lili Zhangzhong, Xin Zhang, Caiyuan Wang, Shirui Zhang, et al.. A Review on the Soil Moisture Prediction Model and Its Application in the Information System. 11th International Conference on Computer and Computing Technologies in Agriculture (CCTA), Aug 2017, Jilin, China. pp.352-364, 10.1007/978-3-030-06137-1_32 . hal-02124261

\section{HAL Id: hal-02124261 \\ https://hal.inria.fr/hal-02124261}

Submitted on 9 May 2019

HAL is a multi-disciplinary open access archive for the deposit and dissemination of scientific research documents, whether they are published or not. The documents may come from teaching and research institutions in France or abroad, or from public or private research centers.
L'archive ouverte pluridisciplinaire HAL, est destinée au dépôt et à la diffusion de documents scientifiques de niveau recherche, publiés ou non, émanant des établissements d'enseignement et de recherche français ou étrangers, des laboratoires publics ou privés. 


\title{
A review on the soil moisture predictionmodel and its application in the
}

\section{Information system}

Wengang Zheng ${ }^{1}$, Lili Zhangzhong ${ }^{1}$, Xin Zhang ${ }^{1}$, Caiyuan $\mathrm{Wang}^{2}$, Shirui Zhang ${ }^{1}$, Shijun Sun ${ }^{4}$, Hongfei $\mathrm{Niu}^{3(\Delta)}$

1 National Engineering Research Center for Intelligent Equipment in Agriculture, Beijing Academy of Agriculture and Forestry Sciences, Beijing 100097, China

zhengwg@nercita.org.cn, zhangzll@nercita.org.cn, zhangx@nercita.org.cn, zhangsr@nercita.org.cn

2 Beijing Water-affair Authority, Beijing 100097, China

Caiyuanwang555@163.com

3 Liaoning Water Conservancy Vocational College, Shenyang Liaoning, 110122, China

Crystalove202707@126.com

4 College of Water Conservancy, Shenyang Agricultural University, Shenyang Liaoning, 110866, China

sunshijun2000@yeah.net

\begin{abstract}
Soil moisture as an important parameter index in agricultural production is not only concerned with agricultural production, but also plays an important role in alleviating water shortage. This paper analyzes the principle of moisture content prediction, reviews the study of soil moisture prediction in different scales, lists the applications of moisture content prediction in practice and prospects the development trend of moisture content prediction.
\end{abstract}

Keywords: Soil moisture $\cdot$ Prediction principle $\cdot$ Predicting scales $\cdot$ Practical application $\cdot$ Development trend

\section{Introduction}

China is a traditional agricultural country, with a total planting area of 16634.4 million $\mathrm{hm}^{2}$, dry crop sowing area of 13612.83 million $\mathrm{hm}^{2}$, while the effective irrigation area is only 6587.26 million $\mathrm{hm}^{2}$. Most of the country is in drought-farming areas, and the effective irrigation area is less than $50 \%{ }^{[1]}$. In 2016, China's total water consumption was 604.02 billion $\mathrm{m}^{3}$, including $13.6 \%$ of domestic water consumption, $21.6 \%$ of industrial water consumption, $62.4 \%$ of agricultural water use, $2.4 \%$ of the ecological environment use, with a large proportion in agricultural water use in total ${ }^{[2]}$.

The problem of food and water shortage is becoming the main problem affecting the development following with the development of economy and the rapid population growth. The limited water

$1^{\text {st }}$ Author: Wengang Zheng (1974-),male,native place: Weihai, Shangdong,doctor, E-mail:

zhengwg@nercita.org.cn

Corresponding Author: Hongfei Niu(1988-),male,native place: Shenyang Liaoning,master, E-mail:

crystalove202707@126.com 
resources and the growing water demand make the problem of water shortage worse and worse. Water use in agriculture account for $62.4 \%$ in total while the effective utilization coefficient of irrigation water in farmland is 0.542 , which proves there is a lot of research space for agricultural water use.

Appropriate and timely irrigation to a certain extent improves the efficiency of agricultural irrigation water use, so we must be able to master the soil moisture content timely and accurately, and to predict the change trend of soil moisture in a period of time. Which can help us irrigate greater area with limited water resources, increase production with less water and alleviate the shortage of water resources.

\section{2 prediction mechanism of moisture content}

Soil moisture is affected by climate, evaporation, rainfall, temperature and other factors, on the one hand, it is in dynamic movement and on the other hand, its movement trend is influenced by related factors. So we can get the dynamic situation of soil moisture indirectly through calculation and derivation by mastering the influencing factors. The general principle can be simplified as shown in figure 1: under the effect of rainfall, evaporation consumption, irrigation and crop consumption, the soil moisture dynamic changes, and factors such as light, temperature, wind speed to a certain extent affect the speed of this change, so, we can learn some easily acquired factors such as rainfall, irrigation, illumination, temperature, wind speed and so on to indirect understand soil moisture change process, realize the prediction of soil moisture. The prediction model can be divided into accurate model and fuzzy

model.

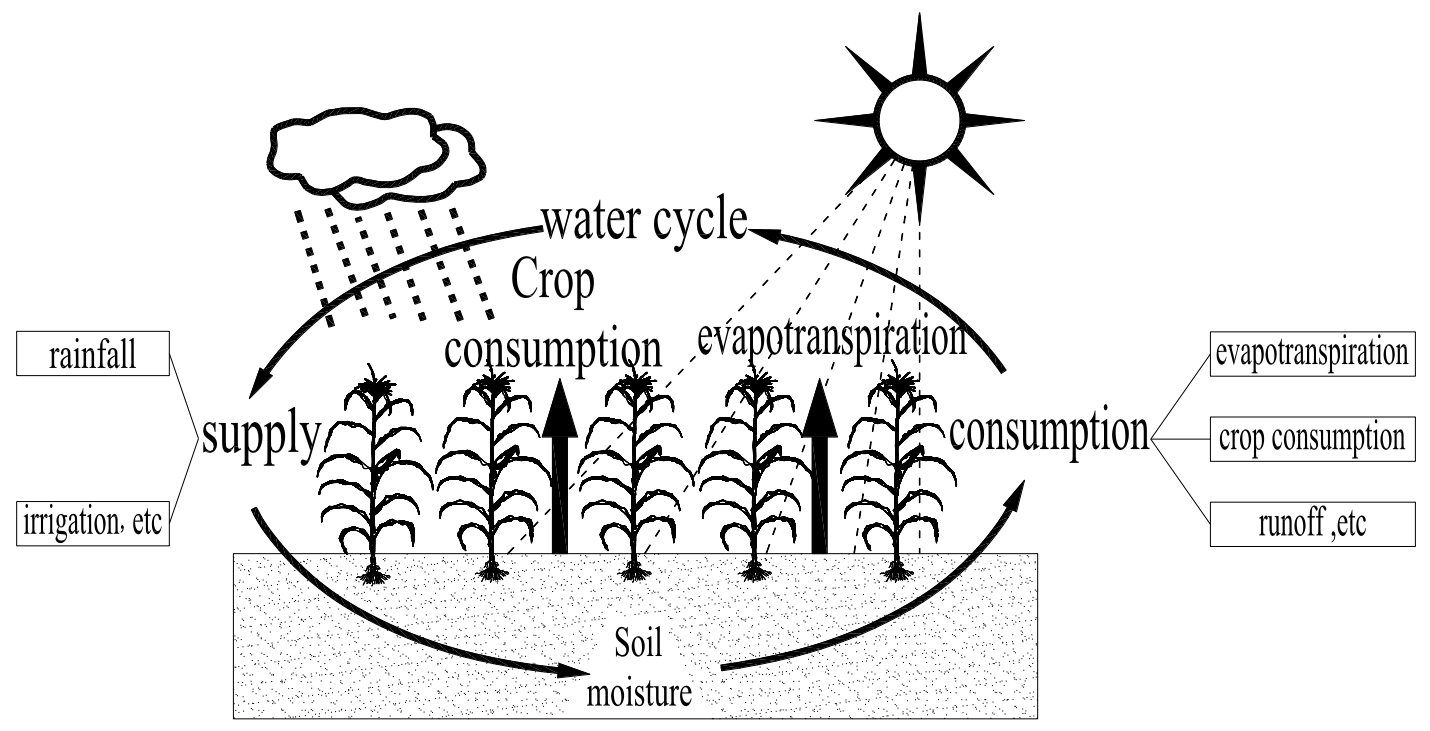

Fig.1 Principle diagram of soil moisture content prediction

The accurate model has definite model expression, such as water balance model, soil hydrodynamic model, water regression model, time series model, etc.

The soil water balance model with clear expression, regard the crop root in the soil as a whole. Under the action of rainfall, irrigation, crop consumption, evaporation and groundwater recharge, the soil moisture content keep balance dynamically ${ }^{[3]}$. The model expression is as shown in formula (1) :

$$
W_{i-1}+P_{e i}+I_{i}+K_{i}-\left(E T_{c i}+W_{i}\right)=0
$$


where $W_{i-1}$ and $W_{i}$ is the amount of water stored in the soil layer on the day of $i-1$ and $i$, $P_{e i}$ is effective rainfall on the day of $i, I_{i}$ is irrigation amount on the day $i, K_{i}$ is supplement from groundwater on the day $i$ and $E T_{c i}$ is water requirement of crop on the day $i$.

The soil water motion model grasps the moisture content of soil by determining its initial conditions and boundary conditions ${ }^{[4]}$. The model expression is shown in formula (2) :

$$
\frac{\partial \theta}{\partial t}=\frac{\partial}{\partial z}\left[D(\theta) \frac{\partial \theta}{\partial z}\right]-\frac{\partial k(\theta)}{\partial z}-S(z, t)
$$

where $\theta$ is the volumetric soil water content $(\%)$; t is time (h), $\mathrm{z}$ is Vertical coordinates, with the soil surface as the reference surface, positive direction downward $(\mathrm{cm}) ; D(\theta)$ is soil water $\operatorname{diffusivity}\left(\mathrm{cm}^{2} / \mathrm{h}\right) ; \mathrm{k}(\theta)$ is soil hydraulic conductivity $(\mathrm{cm} / \mathrm{h}) ; \quad S(z, t)$ is soil water absorption by root $(1 / \mathrm{h})$, it shows the volume of water absorbed from the unit volume soil in unit time.

The principle of exponential depletion model is shown in formula (3). Through the water consumption of a period of time and the accumulation and reduction of soil moisture at the end of the period, the change of soil moisture is mastered ${ }^{[5]}$.

$$
W_{2}-W_{1}=P_{e}+I-E T+K-C
$$

where $W_{1} 、 W_{2}$ is the amount of soil water at time $t_{1}$ and $t_{2} \mathrm{~mm} ; P_{e}$ is effective rainfall during the period, $\mathrm{mm}$; $I$ is irrigation volume during the period, $\mathrm{mm}$; $E T$ is crop evapotranspiration, $\mathrm{mm}$; $K$ is supplement from groundwater, $\mathrm{mm} ; C$ is drainage volume during the period, $\mathrm{mm}$ 。

Time series model, as shown in the formula (4). The operation steps are roughly divided into the establishment of a self-regression model, correlation analysis, order and model diagnosis, and the accurate fitting of the model and measured values ${ }^{[6]}$.

$$
X_{t}-\mu=\varphi_{1}\left(X_{t-1}-\mu\right)+\varphi_{2}\left(X_{t-2}-\mu\right)+\cdots+\varphi_{q}\left(X_{t-q}-\mu\right)+e_{t}
$$

where ${ }^{\mu}$ is the the mean of the time series; $\varphi_{1}, \varphi_{2}, \cdots, \varphi_{\mathrm{q}}$ is coefficient; the current value of time series $\left\{X_{t}\right\}$ is the linear combination of its recent q - order delay and $e_{t}$.

Different with the several kinds of models above, neural network model has no clear expression model. The model simulates biological neurons and realizes flexible accurate fitting with sample data through constant correction error of training. In the neural network, the neural network (BP) neural network and the radial basis (RBF) neural network are commonly used, the network structure are shown in fig. 2 and fig.3. The structure can be divided into three layers, named input layer, hidden layer and output layer, the input layer accepts outside of the input signal, passes it to the hidden layer, and hidden layer is the area where neurons exist and operate. The network realize to gather information of learning, and pass the final result to the output layer through the different operation mechanism of reverse transmission mechanisms such as the error of BP network and local approximation principle of 
RBF network ${ }^{[7]}$.

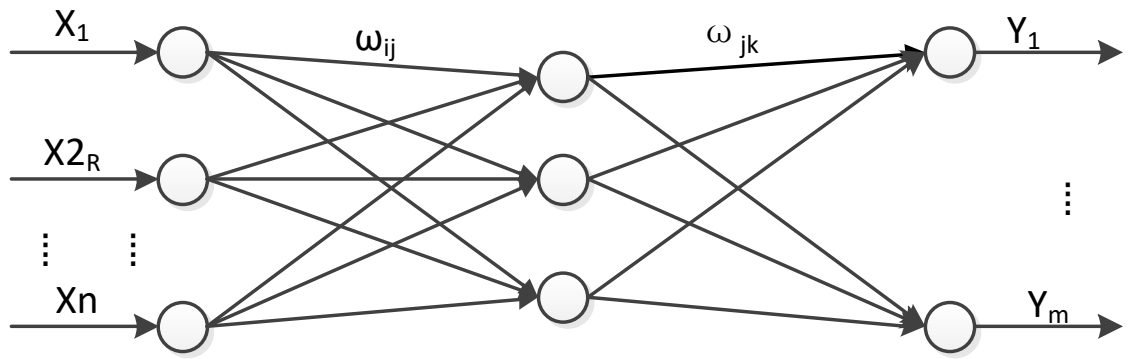

Input layer Hidden layer Output layer

Fig.2 BP neural network structure diagram

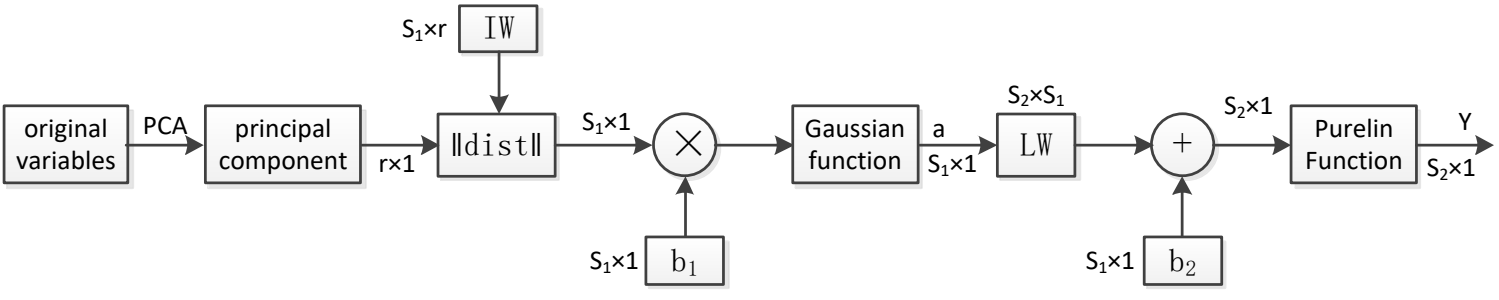

Fig.3 RBF neural network structure diagram

Different types of model has its own characteristics, the accurate model has a definite model expression with clear quantity relationship, the operation is more convenient, for each model has an independent model expression, it lacks flexibility. While neural network model has no clear expression, the relationship between variables can be many kinds, it has strong flexibility and high precision, but the model needs to have a large amount of data for training, besides the establishment of the model is more complex and not easy to operate.

\section{3 research status}

The prediction of soil moisture content is generally divided into soil scale, farmland scale and regional scale. Soil scale is the study for research within the scope of $1-10^{2} \mathrm{~m}^{2}$, generally it dose not consider the space such as meteorology, soil and crop variability. Farmland scale is the study for research within the scope of $10^{2} \sim 10^{6} \mathrm{~m}^{2}$, with little change in meteorological factors generally, if the spatial distribution of the factors such as soil and crops even, it can also regard as the scale of soil. Regional scale is the study for research more than $10^{6} \mathrm{~m}^{2}$, the spatial variability is large, it needs to consider factor's spatial change such as meteorology, soil and crop.

\subsection{On the soil scale}

The study of soil moisture content on soil scale was early, in the 1970s, through the research Lewin found that the root system activity in wheat growing season areas is mainly concentrated in the region of the buried deeply $0-90 \mathrm{~cm}$, and the relationship between soil water rate on the layer and soil water storage presents a linear relationship, and empirical model of the soil moisture forecast is constructed based on it ${ }^{[8]}$. Domestic research start earlier in the $1950 \mathrm{~s}$ to $1960 \mathrm{~s}$, some scholars carried out on several main soil types positioning and orientation dynamic monitoring soil moisture content, which laid a solid foundation for the soil moisture content predicting.

\subsection{On the farmland scale}

\section{Study abroad}


With the development of research and the development of science and technology, the method of predicting soil moisture content is becoming more and more diversified. The research scale is gradually being overextended to the farmland scale by the soil scale. Scott $\mathrm{C}$ A et al. used the two parameters of saturated water content and evaporation coefficient to establish an exponential model for predicting soil moisture content, and realized the prediction of soil moisture content under farmland scale ${ }^{[9]}$.Claudia Notarnicola applied Bayes and neural network in two ways respectively to simulate the remote sensing information retrieval. Soil moisture is the output value, and the prediction error of moisture content and contrast in two ways was compared, to get the advantages and disadvantages of different methods and applicable conditions ${ }^{[10]}$. And Abhishek Pandey et al. from India combined artificial neural algorithm with the application of microwave data, such as to forecast the soil moisture content. Through transmitting and receiving microwave data by $\mathrm{x}$-band microwave scatter ometer under different soil conditions, the fitting and training of artificial neural network model was implemented. More suitable training methods to complete on soil water content and soil surface roughness prediction were selected by comparing the difference between prediction and actual measured values by different training methods on soil water content and soil surface roughness ${ }^{[11]}$. Yi Lung et al. improved micro-strip ring resonant sensor to measure soil moisture, they set up tests to microwave measurement of soil moisture in different soil, and predicted by transforming reflection coefficient of the humus soil and sand under different water content ${ }^{[12]}$. According to the study of the basic soil properties and the water content in the soil, Pedotransfer Functions (PTF) can be established to predict the soil moisture content, and the practice is carried out in the case of the vineyard in New South Wales, Australia ${ }^{[13]}$.

\section{Domestic Research}

For the farmland scale soil moisture forecast needs to consider less influence factors relatively, and the spatial variation of soil moisture is small, so it developed rapidly, and all kinds of forecasting methods are becoming mature in the unceasing research. Jinlong et al. established BP neural network model to forecast soil moisture of winter wheat in Xuzhou agricultural weather test station in Huaibei district, Jiangsu province. In the experiment, 51 ten-day observed data was collected during the experiment station of two adjacent medium drought years continuous. Through fitting, training, and the finally checking, the model implemented the prediction of soil moisture ${ }^{[14]}$. Ding Hui, et al, has realized the prediction of soil moisture by the application of support vector regression machines based on bacterial foraging optimization algorithm which provided support for agricultural production $^{[15]}$.Shao-hui Yang predicted the soil water content of different depth value through establishing time series model in Beijing Daxing district Lu Cheng sites, and confirmed the time series model could well realize the soil moisture forecast by comparing and analyzing the estimated value of the model with the existing data ${ }^{[16]}$.Changhua Chen explored he prediction model of long-term soil moisture content of tobacco growth and proposed the neural network model based on principal component analysis (PCA) and radial basis function (RBF) in the mountain area of Liangshan Kuaili-Mountain. The model introduced PCA on the basis of traditional neural network, which improved the operation efficiency and operation precision of the model ${ }^{[17]}$. Ji Ronghua has established a multi step prediction model of soil moisture by using multi valued neural network based on multi valued neural network, which provides scientific guidance for the designation of irrigation system ${ }^{[18]}$. There is also a short term forecast on soil moisture in farmland, which proves the feasibility of establishing time series model by gray correlation analysis to predict the short-term soil moisture content $^{[19]}$. 


\subsection{0n the regional scale}

With the deepening of the research on soil moisture, the diversification of prediction methods, and developed from the traditional statistical study of spatial variability of constant progress, people are no longer on the study of soil moisture content with length scales and farmland soil, has the spatial variability of regional prediction gradually into the people's research.

\section{Study abroad}

The development of 3S technology abroad is relatively early, after the 1980s it has obtained the full development. In the 1990s, the utilization rate of soil moisture content prediction in regional scale greatly increase, and the prediction accuracy is becoming higher and higher as meteorological satellite remote sensing is becoming increasingly important, especially the increasing maturity of remote sensing and GIS, GPS integration and application technology

Martin Aboitiz et al. established a time series model based on actual data from western Colorado, which predicted soil moisture content in this area after fitting and calibration. The predictive value and error information provided by the model can guide the formulation of irrigation systems and take full account of the inherent risk of crop damage under limited water, energy, labor and capital ${ }^{[20]}$. A.Weimann et al. estimate the soil moisture content according to ERS-1 SAR data in the east Germany's wetted loess area. The information of soil moisture content is accurately determined by satellite data, which provides another powerful prediction method for the regional prediction of soil moisture content ${ }^{[21]}$.St. Elmaloglou et al. made a simulation study of grassland soil water in blu region, Belgium using one-dimensional mode SWAP93. The model introduced variable Smax, which is linearly dependent with depth $\mathrm{z}$. And the study showed that, the error between predicted value of soil moisture content and actual value of the section with depth greater than $30 \mathrm{~cm}$ is smaller, while the measurement value was lower with depth smaller than $30 \mathrm{~cm}$ for the existence of near-surface fractures results in the loss of water ${ }^{[2]}$. Sulebak et al. studied the relationship between soil moisture content and moisture index, soil moisture content and topographic characteristic parameters, and established corresponding models ${ }^{[23]}$.Y.Yamaguchi et al. established two soil moisture models, a water balance model and statistical model ,based on the years of the sahel observation, and proved that both models have high accuracy and stability in predicting soil moisture content ${ }^{[24]}$. Hongli Jiang et al. Analyzed the feasibility of applying neural network to estimate soil moisture content. They take the data from the university of Maryland, the U.S. geological survey and the national center for environmental as the input of neural network and compared the correlation between the output results and the measured data after simulation. The results showed that there was a strong correlation between the spatial mean water content data, which provided a strong case for the regional prediction of moisture content ${ }^{[25]}$.Amin Elshorbagy et al. described the interaction between the boundary layer and atmosphere of the soil surface by direct energy balance and water balance by direct energy balance and water balance in the subarabaskar basin in alberta, Canada. Widely explored the application of data driven model that artificial neural network model to simulate the complex soil water movement, according to the different layers of rainfall, temperature, net radiation, and to simulate the soil humus soil temperature and soil magnetism of soil volumetric water content. The ground temperature is the most influential state variable describing soil moisture in the absence of time delay meteorological variables and the close relationship between soil thermal characteristics and water status is highlighted ${ }^{[26]}$. Barbara Cafarelli et al. incorporated the covariate into the predictor, which improves the prediction accuracy of the model, and makes a practical prediction for a field in southeastern Italy ${ }^{[27]}$. Using the Hydrus-1D model, Min Chen et al. simulated the sudden water dynamics in two basins of Stanley and Krui, which proved its 
feasibility in the prediction of soil humidity ${ }^{[28]}$.

\section{Domestic Research}

In the 1990s, remote sensing detection technology of soil moisture by microwave remote sensing and infrared remote sensing has come a long way with the application of $3 \mathrm{~S}$ technology deeply, following the macroscopic monitoring of soil moisture and drought has made great progress and various studies of soil moisture content in the region have emerged. Mingsheng Li et al. established the dynamic balance specific to the actual condition of lacking in rainstorm between soil water content, effective rainfall, irrigation amount, supplement from groundwater and crop water storage in the Hui Nong county of northern Yinchuan Plain in Ningxia province. The soil water balance method was applied to the soil moisture prediction, and the soil layers above the crop root zone were regarded as a whole. By calculating the water-consumption of crops and combining it with the actual measured data, it is possible to predict the soil water content accurately at the end of the period when the precipitation is low (the soil moisture does not exceed the saturated soil moisture) ${ }^{[3]}$.Yonghong Liu et al. predicted the soil water changes in the future according to the forecast factor of meteorological elements in the future period. The prediction combined the principle of soil moisture balance, double crop coefficient and the principle of Priestley - Taylor model. The visualization of soil moisture content in Beijing area is realized based on the localization of correction of model parameter, the introduction of RS and GIS space technology, which obtained the parameters of vegetation type, albedo, vegetation coverage and soil texture in Beijing area ${ }^{[29]}$. Alun Li took Beijing Tongzhou district as the research object, combined comprehensive utilization distance method, Ordinary Kriging, co-Kriging and stochastic simulation method four spatial analysis methods to analyze the soil moisture content of different depths in the region. Besides, the advantages and disadvantages of several methods and the conditions of use are analyzed, which provides a strong basis for spatial prediction analysis of regional moisture content ${ }^{[30]}$. Zhang Xiaoyue, based on $\mathrm{VC}++$ and Fortran programming language, realized the farmland soil moisture monitoring and forecasting system in Liaoning province ${ }^{[31]}$. Similarly, the two provinces in Hubei and Hunan provinces were selected as the research area. Wang Sheng realized the prediction and Simulation of crop evapotranspiration based on GEP and related geographic location information ${ }^{[32]}$.

\section{Practical application}

There are not only applications which directly use the theories, but also those of soft form in the practices of soil moisture prediction both at home and abroad. For instance, it can be used for providing guidance for spring plowing and irrigation, providing basises for wetland management and moisture forecasting software and systems founded on that. There are some examples of applications listed in Tab.1

Tab.1 Examples of soil moisture content prediction practice

\begin{tabular}{cccc}
\hline NO. & Research Method & Representative Personage & Specific Application \\
\hline 1 & Neural Network & Li Qian & Guiding Spring Plowing \\
2 & Network cell automata & Xiaodong Song & Conducting Irrigation \\
3 & SWAP Modeling & Héctor Aguilera & Wetland Management \\
4 & Field Water Balance & Yonghong Liu & Soil Moisture Forecast \\
5 & SPAC System & Wei Tu Technology & Part of The Automated \\
& & & Agriculture \\
6 & Aanvlsis Network & Soil Climate Aanvlsis Network & Conducting Irrigation and
\end{tabular}


The table lists several practical applications of soil moisture prediction ranging from small stand-alone models to large grid systems such as SWAP model. In order to achieve the goal of scientific management of wetlands, Héctor Aguilera et al. mastered wetland soil moisture by establishing this model. The specific settings of this model are achieved by means of setting the upper boundary condition and the lower boundary condition, and inputting certain data on weather and crops. Fig. 4 shows the initial interface of the software. Tianjin has established a monitoring and early warning system for soil moisture rather than the SWAP standalone model. As is shown in Fig. 5, soil moisture under different depths and different periods can be predicted in different ways through the moisture prediction module of the system. In order to propose scientific technical remedial measures and suggestions for the disaster prevention, the drought resistance and the efficient irrigation, the system accomplished the automatic upload, storage, query and summary of the monitoring data and the visualized expression and timely announcement of the moisture early warning information through the construction of the platform. This system can provide the basis for the government's decisions on flood control, drought resistance, disaster prevention and disaster relief. Analogously, the United States has Soil Climate Aanvlsis Network which can provide the real-time monitoring and simulated data of soil moisture for the local authorities to guide the irrigation or provide the basis for drought resistance.

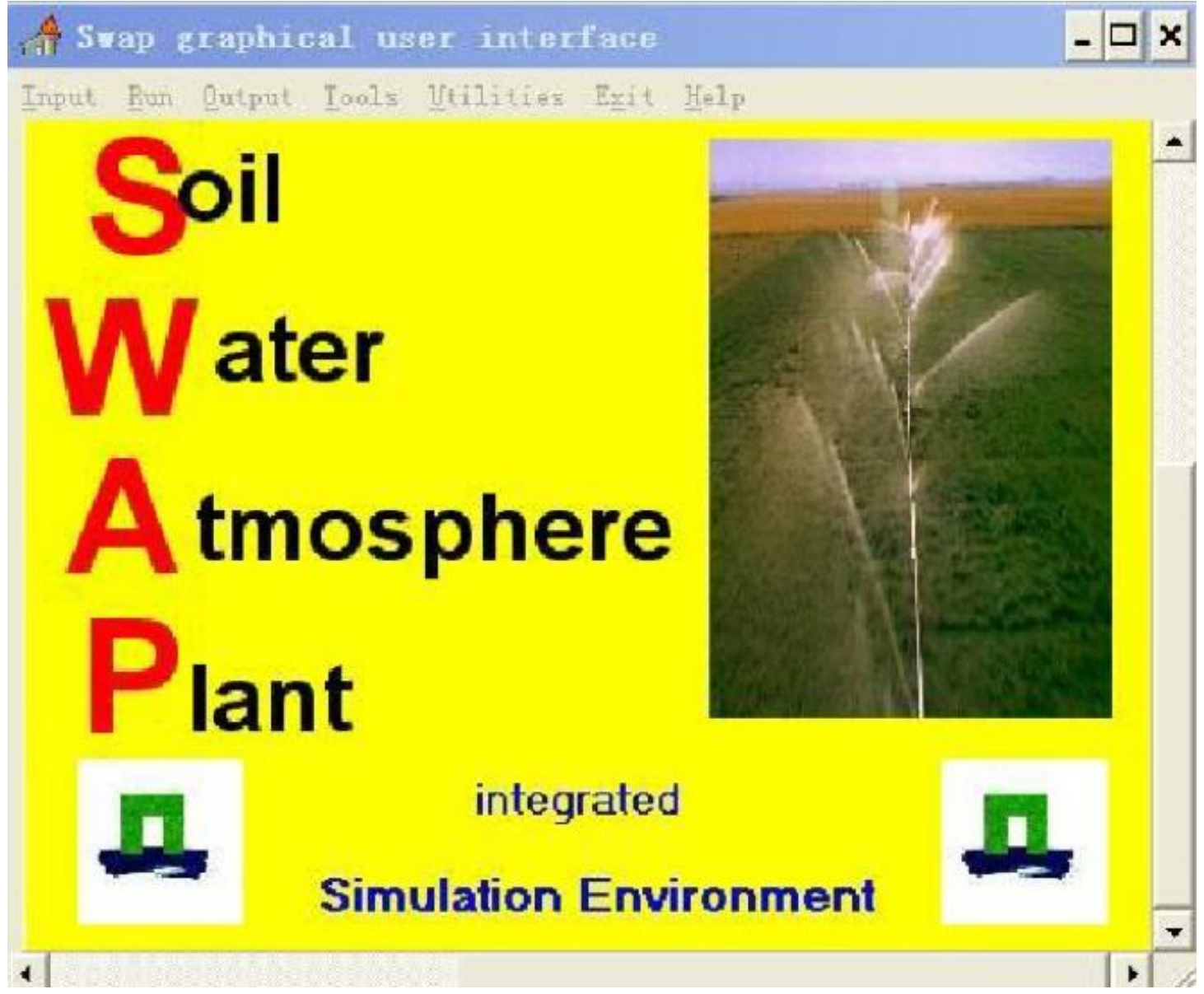

Fig. 4 SWAP Operation Interface 


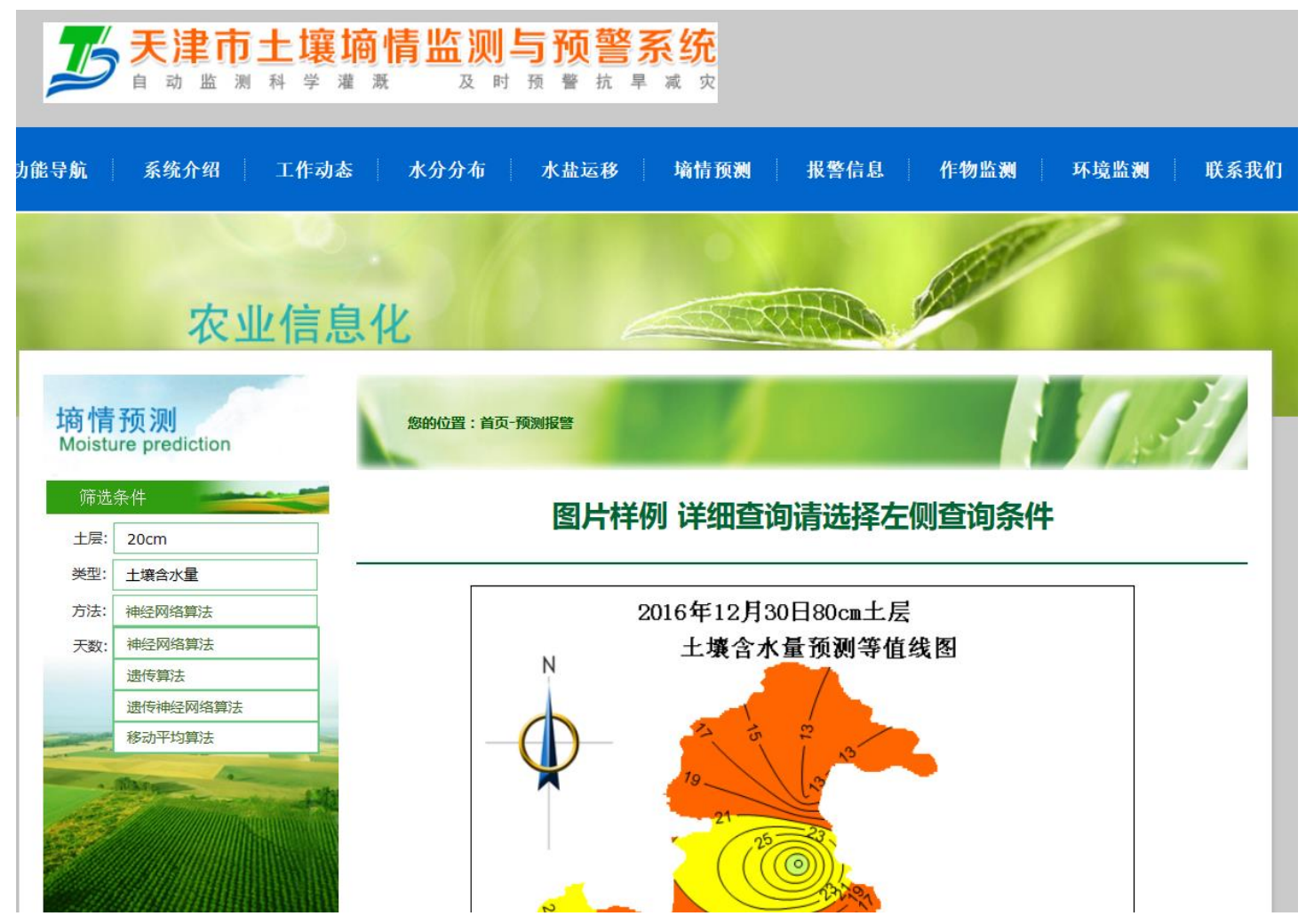

Fig. 5 Monitoring and Early Warning System for Soil Moisture in Tianjin

\section{Development tendency}

The progress of science and technology led to the rapid development of soil moisture prediction technology. Small-scale moisture forecast and studies that remain in the level of scientific researches and experiments have been unable to keep up with the pace of the era. Aiming at being applied in practice, the soil moisture prediction technology will tend to consider more influencing factors, to explore greater scale, to use more advanced methods and to integrate with more technologies from other fields in the future.

\subsection{Multi-source data and large scale}

With the increase of monitoring stations, the popularization of the technologies such as satellite and GIS and the emergence of other new technologies, the regional data can be obtained more easily, which provides strong guarantee of data for large-scale moisture prediction. Meanwhile, more factors associated with soil moisture are gradually being found and studied. Therefore, the prediction of soil moisture should be an all-round prediction with more factors, larger scale and higher precision in the future, which can reveal the influencing factors and temporal and spatial variability of soil moisture more effectively.

\subsection{Multi-method and high intelligence}

Technologies from multi-field will be applied to moisture prediction in the future to accomplish multi-method forecast future soil moisture prediction will use multi-field technology to achieve multi-method forecast such as the one mentioned earlier that using microwave reflection and soil color appearance under different soil texture and different water consumption to predict soil moisture. In addition, the process of forecast will be more intelligent, which means that many of the procedures in the forecast will be automatically completed by the model or program. For instance, the model can 
automatically call the required data according to the need of operation by being linked to the weather platform.

\subsection{Applications in Multi-field}

The moisture prediction should be more closely combined with the practice of production in the future, for example, give guidance to farmers in spring sowing by predicting the soil moisture in spring. Besides, formulate a flood control program and schedule precipitation to avoid or reduce the occurrence of floods by combining soil moisture prediction with weather prognosis in summer. Moreover, determine the harvest time on the basis of (according to the relation between the crop's requirement for moisture and yield rather than the appearance in autumn. Furthermore, observe the moisture data and master the dynamic changes in moisture to get prepared for the overwintering of winter wheat and next spring sowing in winter.

Acknowledgement. The research was supported by the National Key Research and Development Program of China (2016YFC0403102), the Innovation ability construction project of Beijing academy of agriculture and forestry sciences (KJCX20170204) and (KJCX20151411), and Beijing postdoctoral training fund.

\section{References}

1. China Water Resources Bulletin 2016 [DB/OL]. http://www.mwr.gov.cn/sj/\#tjgb

2.National Bureau of Statistics of the People's Republic of China[DB/OL]. http://data.stats.gov.cn/easyquery.htm?cn=C01

3. Mingsheng Li,Zhen Liu. Application of soil water balance model in soil moisture prediction [J].Water Resources \& Hydropower of Northeast China,2005,23(246): 49-51.

4. Shaozhongn Kang,Fucang Zhang,Yinli Liang. Research on the Forecast Method of Soil Water Dynamic Process in Corn-land[J]. Acta Ecologica Sinica,1997,17(3): 245-251.

5. Shenghai Pu, Xinlin He, Chunyan He,et al. Study on Soil Moisture Forecast Method Based on Exponential Depletion Relations for Cotton Drip Irrigation under Mulch in Xinjiang Autonomous Region [J]. Water-saving Irrigation,2008,8: 5-7.

6. Dongmei Bai,Mancai Guo,Zhongsheng GUO, et al. Application of time series autoregressive model in soil moisture prediction [J]. Soil and Water Conservation of China ,2014,2: 42-46.

7. Defeng Zhang,et al. Matlab neural network application design[M].Beijing: China Machine Press,2012.

8. Lewin J.A simple soil water simulation model for assessing the irrigation requirements of wheat [J] . Israel $\mathrm{J}$ Agric Res,1972, 22( 4) : 201- 213.

9. Scott C A, Bastiaanssen W G M , Ahmad M . Mapping root zone soil moisture using remotely sensed optical imagery [J].Journal of Irrigatio nand Drainage Engineering , 2003, 129( 5): 326- 335 .

10. Claudia Notarnicola, Mariella Angiulli, Francesco Posa,etc. Soil Moisture Retrieval From Remotely Sensed Data: Neural Network Approach Versus Bayesian Method [J].IEEE Transactions on Geoscience \& Remote Sensing, 2008, 46(2):547-557.

11. Abhishek Pandeya, S. K. Jhab, J. K. Srivastavac. Artificial Neural Network for the Estimation of Soil Moisture and Surface Roughness1 [J]. Russian Agricultural Sciences, 2010, 36:428-432.

12. Yi Lung Then,Kok Yeow You,Mohamad Ngasri Dimon.A modified microstrip ring resonator sensor with lumped element modeling for soil moisture and dielectric preditions measurement[J]. Measuremen, 2016, 94:119-125. 
13. Jonathan E. Holland, Asim Biswas. Predicting the mobile water content of vineyard soils in New South Wales, Australia [J]. Agricultural Water Management, 2015, 148:34-42.

14. Long Jin, Ying Luo,Qilong Miu,et al. Study of artificial neural network prediction model of soil moisture in farmland [J]. Acta Pedologica Sinica,1998,35(1): 25-32.

15. Ding Hui,Zhong Yue,Zhang Jun,et al. Application of Support Vector Regression Machines in Soil Moisture Prediction Based on Bacteria Foraging Optimization Algorithm[J]. Bulletin of Soil and Water Conservation, 2016 36(6):131-135.

16. Shaohui Yang,Yiming Wang, Zhengqin Guo,et al. Study of ARIMA model on soil moisture content prediction [J]. Agricultural Research in the Arid Areas, 2006, 24( 2): 114- 118.

17. Changhua Chen,Jun Tan,Jiankang Yin,et al. Prediction for soil moisture in tobacco fields based on PCA and RBF neural network [J]. Transactions of the CSAE,2010,26(8): 85-90.

18. Ji Ronghua,Zhang Shulei,Zheng Lihua,et al. Prediction of soil moisture based on multilayer neural network with multi-valued neurons [J]. Transactions of the Chinese Society of Agricultural 19.Ji Ronghua,Li Xin,Zhang Shulei,et al. Short-term Prediction of Soil Moisture in Field Based on GM(1,1)Model Group[J]. Transactions of The Chinese Society of Agricultural Machinery, 2016 47:401-407.

20. Martin Aboitiz , John W.Labadie. Stochastic Soil Moisture Estimation and Forecasting for Irrigated Fields [J]. Water Resoures Research, 1986, 22:180-190.

21. A.Weimann,M.Von Schonermark,A.Schumann,etc. Soil moisture estimation with ERS-1 SAR data in the East-German loess soil area[J]. International Journal of Remote Sensing,1998,19(2):237-243.

22. St.Elmaloglou, N.Malamos. Simulation of soil moisture content of a prairie field with SWAP93 [J]. Agricultural Water Management, 2000,43:139-149.

23. Sulebak J R, Tallaksen L M , Erich sen B. Estimation of a real soil moisture by use of terrain data [J] . Geogr Ann, 2000,82( 1): 89- 105.

24. Y.Yamaguchi,M.Shinoda.Soil Moisture Modeling Based on Multiyear Observations in the Sahel[J].Journal Of Applied Meteorology,2002,41:1140-1146.

25. Hongli Jiang,William R.Cotton.Soil moisture estimation using an artificial neural network: a feasibility study

[J]. Canadian Journal of Remote Sensing,2004,30(5):827-839.

26. Amin Elshorbagy,K. On the relevance of using artificial neural networks for estimating soil moisture content [J]. Journal of arid Land,2008,362:1-18.

27. Barbara Cafarelli, Annamaria Castrignano`,Daniela De Benedetto ,et al. A linear mixed effect (LME) model for soil water content estimation based on geophysical sensing: a comparison of an LME model and kriging with external drift [J]. Environmental Earth Sciences, 2015 ,73:1951-1960.

28. Min Chen, Garry R. Willgoose,Patricia M. Saco. Spatial prediction of temporal soil moisture dynamics using HYDRUS-1D [J]. Hydrological Processes, 2014,28:171-185.

29. Hongbin Liu,Wei Wu,Chaofu Wei. Study of Soil Water Forecast with Neural Network [J]. Journal of Soil and Water Conservation,2003,17(5): 59-62.

30. Alun Li,Weizhong Yang,Juan Lu. Spatial analysis methods and application of regional soil moisture [J]. ChineseAgricultural Science Bulletin,2012,28(21): 311-316.

31. Zhang Xiaoyue,Li Rongping, Jiao Min,et al. Research and development of soil moisture monitoring and forecasting system in farmland $[\mathrm{J}]$. Transactions of the Chinese Society of Agricultural Engineering, 2016,32(18):140-146.

32. Wang Sheng,Fu Zhiyong,Chen Hongsong,et al. Using Gene-Expression Programming method and geographical location information to simulate evapotranspiration in Hunan and Hubei Provinces [J]. Chinese Journal of Eco-Agriculture, 2015, 23(4): 490-496. 